\title{
Exogenous salicylic acid ameliorates waterlogging stress damages and improves photosynthetic efficiency and antioxidative defense system in waxy corn
}

\author{
J. WANG, S.H. SHI, D.Y. WANG, Y. SUN, M. ZHU', and F.H. LI \\ College of Agronomy, Specialty Corn Institute, Shenyang Agricultural University, 110866 Shenyang, \\ Liaoning Province, China
}

\begin{abstract}
Salicylic acid (SA) is an endogenous growth regulator. It is vital for the growth and development, photosynthesis, disease resistance, and abiotic stress tolerance of plants. This study aimed to investigate the effects of exogenous SA on photosynthetic characteristics and antioxidant system in the four-leaf-stage waxy corn inbred seedlings SY-MY13 (waterlogging-resistant) and SY-XT1 (waterlogging-sensitive) under waterlogging stress. Waterlogging stress negatively influenced the morphology, plant height, biomass, photosynthetic characteristics, and chlorophyll content of waxy corn seedlings, obstructing their growth and development. SY-MY13 exhibited better growth and photosynthesis than SY-XT1 under waterlogging, this was due to SY-MY13 possessed excellent scavenging ability to reactive oxygen species (ROS). However, the application of exogenous SA could not only reduce the accumulation of ROS and regulate the activities of antioxidant enzymes but also improve photosynthesis in leaves and promote the growth of seedlings. Hence, the results revealed that the potential of SA as a promising exogenous growth regulator mediated physiological and photosynthetic adaptation of waxy corn seedlings under waterlogging stress, which might prove helpful for other plants suffering from waterlogging stress.
\end{abstract}

Keywords: antioxidant enzyme; chlorophyll fluorescence; photosynthetic characteristics; stomatal aperture; waterlogging tolerance.

\section{Introduction}

Waterlogging stress is described as the saturation of soil with water around the crop roots, which is one of the major abiotic factors limiting plant growth, development, and crop yield (Ren et al. 2017, Tian et al. 2019, Panozzo et al.
2019). Waterlogging stress has become a severe problem affecting crop growth and yield worldwide because of the increasing frequency of excessive rainfall, especially at the lack of soil drainage and irregular topography areas (Dar et al. 2018, Zhang et al. 2019a). An estimated $16 \%$ of the fertile areas of the globe annually undergo waterlogging

\section{Highlights}

- Two waxy corn inbred lines were used in this study

- Exogenous SA mediated physiological and photosynthetic adaptation

- Exogenous SA alleviated the waterlogging-induced damages of waxy corn seedlings
Received 22 November 2020

Accepted 12 January 2021

Published online 12 February 2021

${ }^{+}$Corresponding authors

e-mail: xiaozhu211@syau.edu.cn (M. Zhu)

lifenghai@126.com (F.H. Li)

Abbreviations: $\mathrm{CAT}$ - catalase; $\mathrm{Chl}$ - chlorophyll; $C_{\mathrm{i}}$ - intercellular $\mathrm{CO}_{2}$ concentration; $\mathrm{DAB}$ - diaminobenzidine; DM- dry mass; DMSO dimethylsulfoxide; $E$ - transpiration rate; EDTA - ethylenediaminetetraacetic acid; $\mathrm{FM}$ - fresh mass; $\mathrm{F}_{\mathrm{v}} / \mathrm{F}_{\mathrm{m}}-$ maximum quantum yield of PSII; $g_{s}$ - stomatal conductance; MDA - malondialdehyde; NBT - nitrotetrazolium blue chloride; NPQ - nonphotochemical quenching coefficient; $P_{\mathrm{N}}$ - net photosynthetic rate; POD - peroxidase; PPO - polyphenol oxidase; $\mathrm{q}_{\mathrm{p}}$ - photochemical quenching coefficient; Rfd - steady-state fluorescence decay rate; ROS - reactive oxygen species; SA - salicylic acid; SOD - superoxide dismutase; TBA thiobarbituric acid; $\Phi_{\mathrm{PSII}}$ - effective quantum yield of PSII photochemistry.

Acknowledgments: We are grateful for grants from the National Key R\&D Program of China (2018YFD0300300, 2017YFD0300700, 2017YFD0101103).

Conflict of interest: The authors declare that they have no conflict of interest. 
stress (Xu et al. 2016). Maize is considered sensitive to waterlogging stress, especially during the seedling stage (Ren et al. 2018a). Waxy corn, as a fresh vegetable, is extensively planted in China and many other countries, and Asian local and export markets continue to expand (Ketthaisong et al. 2014). Therefore, it is essential to study waterlogging resistance mechanisms of waxy corn to improve its waterlogging tolerance.

Generally speaking, waterlogging stress has a significant impact on the physiological and biochemical characteristics of plants and leads to structural damage and yield reduction (Fukao et al. 2019). Several studies have reported that waterlogging stress inhibits shoot and root growth, causing a significant reduction in reproductive development and biomass (Wollmer et al. 2018, Wang et al. 2019a). Besides, the negative effects of waterlogging stress are mainly due to its impact on the photosynthetic apparatus. Zhu et al. (2015) concluded that a decrease in net photosynthesis, stomatal conductance, and transpiration was observed in two popcorn genotypes under waterlogging stress, and the sensitive plants showed a reduction in chlorophyll (Chl) fluorescence parameters and Chl content. Ren et al. (2018b) showed that waterlogging stress resulted in the disorder of leaf gasexchange parameters and $\mathrm{Chl}$ fluorescence parameters, eventually causing a significant reduction in photosynthetic characteristics.

Oxidative stress occurs with waterlogging due to the production of toxic reactive oxygen species (ROS), such as superoxide radical $\left(\mathrm{O}_{2}^{-}\right)$and hydrogen peroxide $\left(\mathrm{H}_{2} \mathrm{O}_{2}\right)$, leading to peroxidation of membrane lipids, the occurrence of cell damage, alteration in enzyme activity, degradation and denaturation of proteins, change in the photosynthetic electron transport chain, disruption of the activities of reaction centers, and repression of photosynthesis and respiration (Posso et al. 2018, Ren et al. 2018b, Anee et al. 2019, Park and Lee 2019). Plants minimize oxidative stress by producing enzymatic and nonenzymatic antioxidants. The antioxidant enzyme system, such as superoxide dismutase (SOD), peroxidase (POD), and catalase (CAT), alleviate and scavenge waterlogging-induced ROS production from the plant cells (Gill et al. 2019, Jia et al. 2019, Wang et al. 2019b). SOD catalyzes the conversion of $\mathrm{O}_{2}{ }^{-}$ into $\mathrm{O}_{2}$ and $\mathrm{H}_{2} \mathrm{O}_{2}$, while $\mathrm{H}_{2} \mathrm{O}_{2}$ is effectively scavenged by POD and CAT. Furthermore, polyphenol oxidase (PPO), as a defense enzyme, is widespread in plants (Li et al. 2018). PPO activity increases in pigeon pea roots due to waterlogging and is considered to be essential in late responses to waterlogging stress (Bansal and Srivastava 2012).

Salicylic acid (SA) is an endogenous growth regulator. It is vital in plants, including seed germination, growth and development, nutrient uptake and transport, photosynthesis, protein synthesis, enzyme activities, disease resistance, and abiotic stress tolerance (Li et al. 2017, Moravcová et al. 2018, Spormann et al. 2019, Wassie et al. 2020). Previous studies showed that exogenous SA treatment was pivotal in improving waterlogging tolerance in many plants. SA has extremely important effects on the modulation of growth parameters and photosynthetic characteristics. Zhu et al. (2020) reported that SA treatment could inhibit the decrease in Chl content, increase the net photosynthetic rate $\left(P_{\mathrm{N}}\right)$, stomatal conductance $\left(g_{\mathrm{s}}\right)$, transpiration rate $(E)$, and intercellular $\mathrm{CO}_{2}$ concentration $\left(C_{\mathrm{i}}\right)$, and significantly enhance the photosynthetic characteristics of peony leaves under waterlogging stress. Sayed (2014) suggested that SA treatment could increase Chl $a$ and $\mathrm{Chl} b$ contents significantly, which favored lupine growth under waterlogging stress conditions. Cape gooseberry treated with SA had larger biomass compared to waterlogging stress due to the increased leaf area and improved photochemical activity of PSII (Chávez-Arias et al. 2019). SA improves the plant tolerance of stress through the upregulation of antioxidant defense (Fariduddin et al. 2017, Yousefzadeh Najafabadi and Ehsanzadeh 2017). Treatment with SA significantly increased the activities of SOD, POD, and CAT, effectively inhibited the increase in $\mathrm{H}_{2} \mathrm{O}_{2}, \mathrm{O}_{2}{ }^{--}$, and malondialdehyde (MDA) contents, and markedly enhanced waterlogging tolerance in Malus robusta Rehd.; this effect is beneficial to growth up to a point of plants under waterlogging stress (Bai et al. 2009). Similarly, the antioxidant activities of soybean were enhanced by the SA treatment, which might protect plants against oxidative damage under waterlogging stress (Kamal and Komatsu 2016).

Waterlogging tolerance in maize mediated by treatment with different exogenous growth regulators has been explored (Jaiswal and Srivastava 2016, Otie et al.2019, Ren et al. 2019). However, research on the role of exogenous SA application in response to waxy corn waterlogging stress is still lacking. Thus, the primary aims of this study were: (1) to evaluate changes in photosynthetic characteristics and antioxidant enzyme activity in waxy corn seedlings under waterlogging; (2) to explore whether SA improved the tolerance of waxy corn seedlings to waterlogging stress; and (3) to investigate the protective role of SA in waxy corn seedlings under waterlogging stress by comparing ROS accumulation, abilities of antioxidant enzymes, and photosynthetic characteristics. The findings might provide a theoretical basis for SA application increasing the tolerance of waxy corn seedlings to waterlogging stress.

\section{Materials and methods}

Plant material and experimental design: Two waxy corn inbred lines SY-MY13 (waterlogging-resistant) and SYXT1 (waterlogging-sensitive) were used in this study; they were provided by the Specialty Corn Institute, Shenyang Agricultural University, China. The pot experiment was carried out in 2020 at the Research and Education Center of Agronomy, Shenyang Agricultural University. On 12 May, seeds of two inbred lines were sown in pots $(10 \mathrm{~cm}$ diameter at the bottom and $12 \mathrm{~cm}$ high). Each pot was filled with $1 \mathrm{~kg}$ of soil. The soil was collected from the 0 to 20 $\mathrm{cm}$ tillage soil of the experimental field and classified as brown soil with the following properties: $32.45 \mathrm{~g}$ (organic matter) $\mathrm{kg}^{-1}, 121.86 \mathrm{mg}$ (alkali-hydrolyzable nitrogen) $\mathrm{kg}^{-1}, 9.47 \mathrm{mg}$ (available phosphorus) $\mathrm{kg}^{-1}$, and 114.31 $\mathrm{mg}$ (available potassium) $\mathrm{kg}^{-1}$. After seed germination, each pot contained three healthy seedlings. The pots were moved to a rain shelter covered with a polyethylene film 
to exclude natural precipitation during the experiment. Seedlings were irrigated with water to field capacity until the fourth leaf stage. The experiments were conducted in a completely randomized design. Salicylic acid (SA, analytical purity) was obtained from Ryon Biological Technology Co., Ltd. (Shanghai, China). SA was dissolved in distilled water containing $0.01 \%$ Tween-20 to a final concentration of $1 \mathrm{mM}$. Exogenous SA was evenly sprayed on the waxy corn seedlings' leaves. Each inbred line had four treatments: (1) $\mathrm{CK}$ : normal watering condition; (2) $\mathrm{CK}+\mathrm{SA}: 1 \mathrm{mM}$ salicylic acid plus normal watering condition; (3) W: waterlogging stress condition; and (4) W + SA: 1 mM SA plus waterlogging stress condition. The SA treatment started on 6 June. Each inbred line was placed in a plastic box $(61 \times 42 \times 12 \mathrm{~cm}) 24 \mathrm{~h}$ after the beginning of treatment. Water was poured into the plastic box, and a water depth of $3 \mathrm{~cm}$ above the soil surface was maintained in the waterlogging treatment. Each treatment included 40 pots. After waterlogging stress for $7 \mathrm{~d}$, the whole plant and the fully expanded third leaves from the plant bottom were gathered on the final day of the waterlogging treatment for various measurements.

Sampling and growth parameter determination: After waterlogging treatment for $7 \mathrm{~d}$, the fully expanded third leaves from the plant bottom were collected, frozen instantaneously with liquid nitrogen, and stored at $-80^{\circ} \mathrm{C}$ until they were tested. Three whole waxy corn plants were randomly selected from each treatment and washed with water. Each plant was subdivided into shoots and roots, and the measured growth parameters included plant height, root length, and fresh mass (FM) of the shoots and roots. Subsequently, the plants were loaded into the sample bags, placed in a $105^{\circ} \mathrm{C}$ oven for $2 \mathrm{~h}$, and dried at $80^{\circ} \mathrm{C}$ to a constant mass. Then, the dry mass (DM) of shoots and roots was measured.

The photosynthetic pigment content was calculated as described by Wellburn et al. (1994). Fresh fully expanded third leaves of $0.1 \mathrm{~g}$ were thoroughly cut and submerged into $10 \mathrm{~mL}$ of dimethyl sulfoxide (DMSO) in the dark for $48 \mathrm{~h}$ until the leaves were completely faded. The absorbance at 665,649 , and $480 \mathrm{~nm}$ was recorded using a microplate reader (1510, Thermo Fisher, USA), with DMSO used as a blank. The chlorophyll (Chl) and carotenoids contents were calculated using the following equations:

Chl $a\left[\mathrm{mg} \mathrm{g}^{-1}(\mathrm{FM})\right]=\left(12.19 \times \mathrm{OD}_{665}-3.45 \times \mathrm{OD}_{649}\right) \times$ $\times \mathrm{V} /(1,000 \times \mathrm{M})$

$\mathrm{Chl} b\left[\mathrm{mg} \mathrm{g}^{-1}(\mathrm{FM})\right]=\left(21.99 \times \mathrm{OD}_{649}-5.32 \times \mathrm{OD}_{665}\right) \times$ $\times \mathrm{V} /(1,000 \times \mathrm{M})$

$\mathrm{Chl}(a+b)\left[\mathrm{mg} \mathrm{g}^{-1}(\mathrm{FM})\right]=\mathrm{Chl} a+\mathrm{Chl} b$

Carotenoids $\left[\mathrm{mg} \mathrm{g}^{-1}(\mathrm{FM})\right]=\left(1,000 \times \mathrm{OD}_{480}-2.14 \times\right.$ $\times \mathrm{Chl} a-70.16 \times \mathrm{Chl} b) / 220 \times \mathrm{V} /(1,000 \times \mathrm{M})$

where $\mathrm{OD}_{665}, \mathrm{OD}_{649}$, and $\mathrm{OD}_{480}$ are absorbances of the extract solution at 665,649 , and $480 \mathrm{~nm}$, respectively; $\mathrm{V}$ is the total volume of the extract; and $\mathrm{M}$ is the mass of the sample.
Gas-exchange parameters: A portable photosynthesis system LI-6800 ( $L i$-COR Inc., NE, USA) was used to measure the photosynthetic parameters. The fully expanded third leaves were measured with three individual plants per treatment. The $P_{\mathrm{N}}, E, g_{\mathrm{s}}$, and $C_{\mathrm{i}}$ were measured in a controlled chamber $(1 \times 3 \mathrm{~cm})$ in which the $\mathrm{CO}_{2}$ concentration was $400 \mu \mathrm{mol} \mathrm{mol}^{-1}$ and the relative humidity was $50 \%$, with PPFD of $1,500 \mu \mathrm{mol} \mathrm{m} \mathrm{m}^{-2} \mathrm{~s}^{-1}$. Measurements were taken between 10:00 and 11:00 (local time).

Chl fluorescence parameters: Chl fluorescence was measured after adaptation in the dark for $30 \mathrm{~min}$ and imaged using PAM-2500 (Walz, Germany) and a modulated imaging fluorometer (FluorCam FC800, Photon Systems Instruments, Brno, Czech Republic). The measured parameters included maximum efficiency of PSII photochemistry $\left(\mathrm{F}_{\mathrm{v}} / \mathrm{F}_{\mathrm{m}}\right)$, quantum yield of PSII photochemistry $\left(\Phi_{\mathrm{PSII}}\right)$, nonphotochemical quenching coefficient (NPQ), photochemical quenching $\left(\mathrm{q}_{\mathrm{P}}\right)$, and steady-state fluorescence decay rate (Rfd). The Chl fluorescence parameters were measured and calculated as described by Perera-Castro et al. (2018) and Cai et al. (2020).

Stomatal aperture: After waterlogging treatment for $7 \mathrm{~d}$, leaves of two inbred lines receiving four treatments were fixed with $2.5 \%$ glutaraldehyde, and stomatal images were observed using scanning electron microscopy (Regulus 8100, Hitachi, Japan).

Histochemical staining and determination of MDA, $\mathrm{O}_{2}{ }^{-}$, and $\mathrm{H}_{2} \mathrm{O}_{2}$ : Histochemical detection of $\mathrm{MDA}, \mathrm{O}_{2}{ }^{-}$, and $\mathrm{H}_{2} \mathrm{O}_{2}$ was carried out as described by Xia et al. (2009) with some modifications. The fully expanded third leaves were sampled, washed with distilled water, and blotted dry. Then, they were placed in a test tube containing 50 $\mathrm{mL}$ of $0.06 \mathrm{mg} \mathrm{mL}^{-1}$ thiobarbituric acid reaction solution (10\% trichloroacetic acid solution) and incubated at $25^{\circ} \mathrm{C}$ in the dark for $10 \mathrm{~h}$ for MDA detection; $50 \mathrm{~mL}$ of 0.5 $\mathrm{mg} \mathrm{mL} \mathrm{m}^{-1} \mathrm{NBT}$ reaction solution (potassium phosphate buffer, $\mathrm{pH} 7.8$ ) incubated at $25^{\circ} \mathrm{C}$ in the dark for $2 \mathrm{~h}$ for $\mathrm{O}_{2}{ }^{-}$detection; and $50 \mathrm{~mL}$ of $1 \mathrm{mg} \mathrm{mL}^{-1}$ diaminobenzidine reaction solution (Tris- $\mathrm{HCl}$ buffer, $\mathrm{pH} 3.8$ ) incubated at $25^{\circ} \mathrm{C}$ in the dark for $24 \mathrm{~h}$ for $\mathrm{H}_{2} \mathrm{O}_{2}$ detection. The solution in the individual tubes was replaced with bleaching solution (90\% ethanol) and placed in a boiling water bath $\left(90^{\circ} \mathrm{C}\right)$ for $15 \mathrm{~min}$ till the leaves were fully bleached and then photographed. Subsequently, MDA content was determined using the method described by Ohkawa et al. (1979), and $\mathrm{O}_{2}^{-}$and $\mathrm{H}_{2} \mathrm{O}_{2}$ contents were determined using the method described by Xu et al. (2012).

Antioxidant enzyme activities: The fully expanded third leaves $(0.5 \mathrm{~g})$ were sampled and ground in $5 \mathrm{~mL}$ of phosphate buffer $(0.05 \mathrm{mM}, \mathrm{pH} 7.5)$ containing $0.05 \mathrm{mM}$ EDTA and $2 \%(\mathrm{w} / \mathrm{v})$ insoluble polyvinyl pyrrolidone using a mortar and pestle. The homogenized solution was centrifuged at $1,000 \times g$ for $20 \mathrm{~min}$ at $4^{\circ} \mathrm{C}$. The super-natant was used to measure antioxidant enzyme activities. Absorbances were determined spectrophotometrically using a microplate reader (1510, Thermo Fisher Scientific, USA). The SOD 
(EC 1.15.1) and guaiacol POD (EC 1.11.1.7) activities were calculated as proposed by Abedi and Pakniyat (2010), the CAT (EC 1.11.1.6) activity as described by Wang (1995), and the PPO (EC 1.3.3.4) activity as suggested by Pirovani et al. (2008).

Statistical analysis: All the experiments were performed in biological and technical triplicates. Data were analyzed by one-way analysis of variance $(A N O V A)$, and then the least significant difference test was carried out to indicate a significant difference at $P<0.05$ using SPSS 19.0 software (SPSS, Inc., IL, USA). All results were expressed as means \pm standard deviation (SD). Plotting was performed using Origin 2017 software (OriginLab, MA, USA).

\section{Results}

Plant growth and biomass: The phenotypic response of two inbred lines to different treatments is shown in Fig. 1. The growth of SY-MY13 and SY-XT1 seedlings was generally equivalent for SAtreated and SAnon-treated plants under normal watering conditions. Under waterlogging stress, the bottom leaves of waxy corn seedlings showed obvious symptoms of yellowing, especially SY-XT1; some leaves were even damaged and dead. However, spraying with $1 \mathrm{mM}$ exogenous SA effectively alleviated the damage of waxy corn leaves under waterlogging. As shown in Table 1, compared with CK, CK + SA treatments had no significant impact on the heights of waxy corn. The root FM and DM significantly increased in SY-MY13 treated with SA compared with CK. The effects of waterlogging on growth and biomass were similar in the two inbred lines. Compared with $\mathrm{CK}$, waterlogging stress significantly reduced shoot FM and DM by 34.5 and $45.5 \%$ in SY-XT1, respectively, while the root FM and DM of SY-MY13 and SY-XT1 were reduced by 31.8, $50.0,49.6$, and $60.9 \%$. Compared to SY-MY13, SY-XT1 was more sensitive to waterlogging. On the contrary, spraying with exogenous SA effectively improved the growth and biomass accumulation of waterlogged waxy corn. SA treatment resulted in significant and substantial (32.8 and 144.4\%) increases in root FM compared to the waterlogging treatment; root DM increased by 41.6 and $133.4 \%$, respectively.

Photosynthetic pigment content: Compared with CK, $\mathrm{CK}+\mathrm{SA}$ treatment significantly increased the carotenoid content of SY-MY13 and the Chl $b$ content of SY-XT1

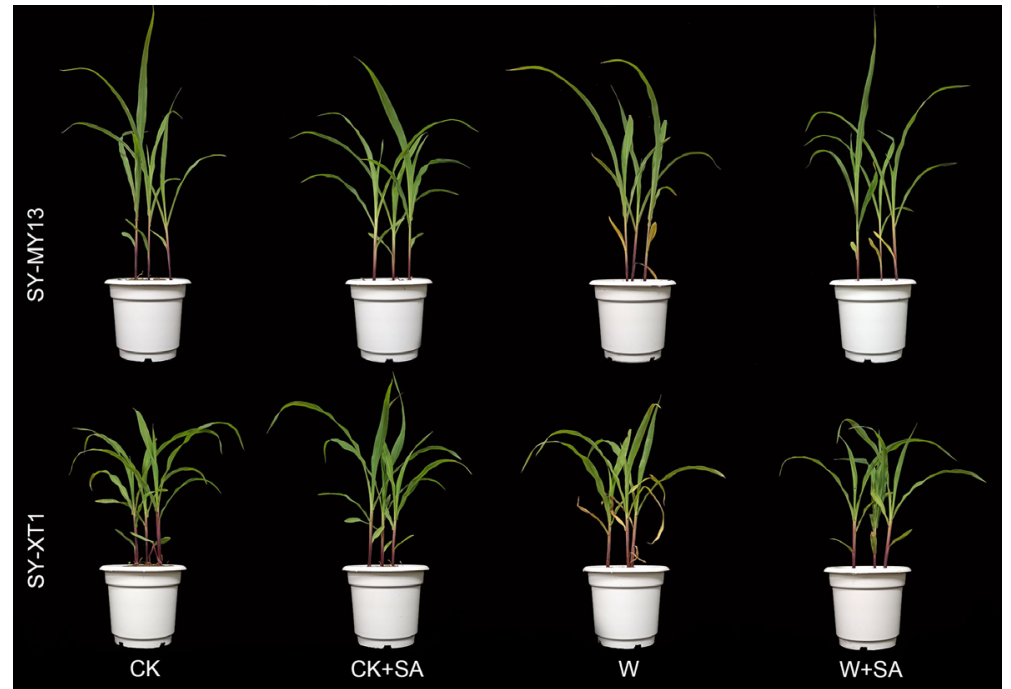

Fig. 1. Effects of salicylic acid on the phenotype of two corn inbred lines under different treatments. $\mathrm{CK}$ - normal watering condition; $\mathrm{CK}+\mathrm{SA}-1 \mathrm{mM}$ salicylic acid plus normal watering condition; $\mathrm{W}$ - waterlogging stress condition; $\mathrm{W}+\mathrm{SA}-1 \mathrm{mM}$ salicylic acid plus waterlogging stress condition.

Table 1. Effects of salicylic acid on the growth and biomass of two waxy corn inbred lines under waterlogging stress. CK - normal watering condition; $\mathrm{CK}+\mathrm{SA}-1 \mathrm{mM}$ salicylic acid plus normal watering condition; $\mathrm{W}-$ waterlogging stress condition; $\mathrm{W}+\mathrm{SA}-1 \mathrm{mM}$ salicylic acid plus waterlogging stress condition. Data represent means $\pm \mathrm{SD}$ of three replicates. For each variable, means with different lowercase letters were significantly different $(P<0.05)$.

\begin{tabular}{lllllll}
\hline Inbred line & Treatment & Height $[\mathrm{cm}]$ & Shoot fresh mass $[\mathrm{g}]$ & Root fresh mass $[\mathrm{g}]$ & Shoot dry mass $[\mathrm{g}]$ & Root dry mass [g] \\
\hline SY-MY13 & CK & $45.0 \pm 2.65^{\mathrm{ab}}$ & $3.78 \pm 0.21^{\mathrm{bc}}$ & $2.64 \pm 0.26^{\mathrm{b}}$ & $0.52 \pm 0.02^{\mathrm{c}}$ & $0.24 \pm 0.01^{\mathrm{b}}$ \\
& CK + SA & $45.3 \pm 2.89^{\mathrm{ab}}$ & $4.07 \pm 0.12^{\mathrm{ab}}$ & $3.18 \pm 0.19^{\mathrm{a}}$ & $0.59 \pm 0.02^{\mathrm{a}}$ & $0.27 \pm 0.02^{\mathrm{a}}$ \\
& W & $43.3 \pm 1.15^{\mathrm{bc}}$ & $3.61 \pm 0.25^{\mathrm{cd}}$ & $1.80 \pm 0.16^{\mathrm{d}}$ & $0.54 \pm 0.00^{\mathrm{c}}$ & $0.12 \pm 0.02^{\mathrm{de}}$ \\
& W + SA & $46.5 \pm 1.32^{\mathrm{a}}$ & $3.75 \pm 0.18^{\mathrm{c}}$ & $2.39 \pm 0.18^{\mathrm{ef}}$ & $0.57 \pm 0.02^{\mathrm{ab}}$ & $0.17 \pm 0.02^{\mathrm{c}}$ \\
SY-XT1 & CK & $37.8 \pm 0.29^{\mathrm{de}}$ & $4.17 \pm 0.09^{\mathrm{a}}$ & $2.24 \pm 0.24^{\mathrm{c}}$ & $0.55 \pm 0.01^{\mathrm{bc}}$ & $0.23 \pm 0.02^{\mathrm{b}}$ \\
& CK + SA & $40.7 \pm 0.58^{\mathrm{cd}}$ & $4.23 \pm 0.23^{\mathrm{a}}$ & $1.54 \pm 0.21^{\text {de }}$ & $0.57 \pm 0.00^{\mathrm{ab}}$ & $0.14 \pm 0.00^{\mathrm{d}}$ \\
& W & $36.3 \pm 2.08^{\mathrm{e}}$ & $2.73 \pm 0.10^{\mathrm{e}}$ & $1.13 \pm 0.06^{\mathrm{f}}$ & $0.30 \pm 0.01^{\mathrm{e}}$ & $0.09 \pm 0.01^{\mathrm{e}}$ \\
& W + SA & $39.0 \pm 1.80^{\mathrm{de}}$ & $3.31 \pm 0.19^{\mathrm{d}}$ & $2.37 \pm 0.32^{\mathrm{bc}}$ & $0.45 \pm 0.00^{\mathrm{d}}$ & $0.22 \pm 0.01^{\mathrm{b}}$ \\
\hline
\end{tabular}


(Fig. 2B,C). Waterlogging stress caused significant decreases in the Chl $a$, Chl $b, \mathrm{Chl}(a+b)$, and carotenoid contents compared with those in $\mathrm{CK}$, and the impact of waterlogging was greater on SY-XT1 than that on SY-MY13. However, the application of SA alleviated waterlogging stress on the biosynthesis of photosynthetic pigments (Fig. 2). Treatments with SA resulted in significant and substantial increases in the contents of Chl $a$, Chl $b$, carotenoids, and Chl $(a+b)$ in SY-MY13 $(22.9,28.9,18.4$, and $24.5 \%$, respectively) and SY-XT1 (33.6, 32.9, 27.2, and $33.4 \%$, respectively) compared with the waterlogging treatment, but it did not eliminate the damage caused by waterlogging. Waterlogging still affected the biosynthesis of photosynthetic pigments.
Gas-exchange parameters: As shown in Fig. 3, the application of exogenous SA significantly increased the $C_{\mathrm{i}}$ of SY-MY13, $P_{\mathrm{N}}$ of SY-XT1, and $g_{\mathrm{s}}$ and $E$ of both under well-irrigated conditions. During the waterlogging treatment, the $P_{\mathrm{N}}, E, g_{\mathrm{s}}$, and $C_{\mathrm{i}}$ of the two inbred lines decreased rapidly, by $71.8,59.5,71.7$, and $24.4 \%$, respectively, in SY-MY13, and by $84.2,51.5,50.5$, and $9.1 \%$ in SY-XT1, compared with the control (Fig. 3). $P_{\mathrm{N}}$ decreased more rapidly in SY-XT1 than that in SY-MY13. The application of SA after waterlogging stress showed better regulation of gas-exchange parameters. $P_{\mathrm{N}}$ increased 2.3-fold and 7.5-fold in SY-MY13 and SY-XT1, respectively, under waterlogging with SA treatment compared with non-SA treatment (Fig. 3A).
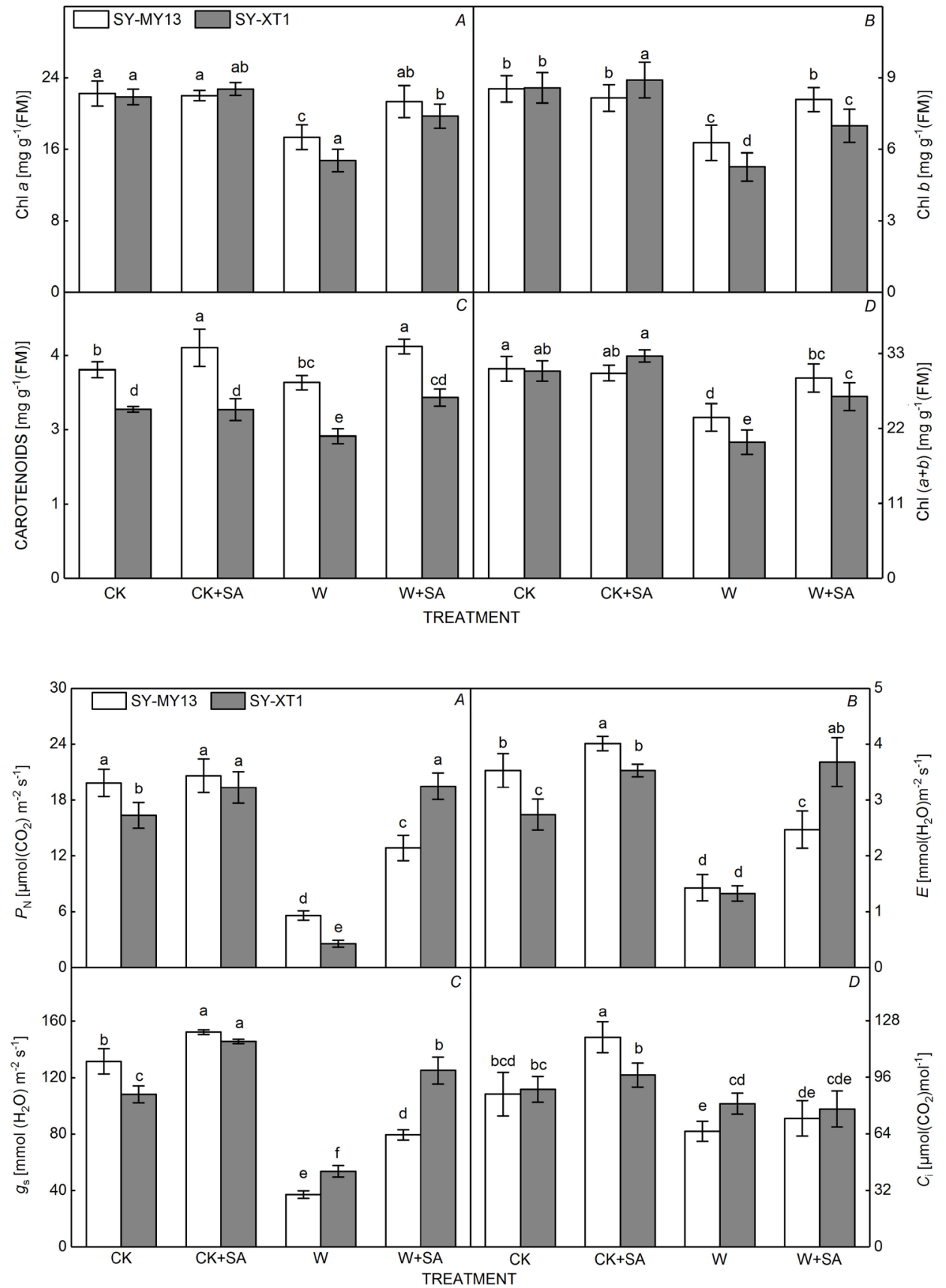

Fig. 2. Effects of salicylic acid on $(A)$ chlorophyll (Chl) $a$; (B) $\mathrm{Chl} b$; (C) carotenoids; and (D) $\mathrm{Chl}(a+b)$ contents in two waxy corn inbred lines under waterlogging conditions. $\mathrm{CK}-$ normal watering condition; $\mathrm{CK}+\mathrm{SA}-1 \mathrm{mM}$ salicylic acid plus normal watering condition; $\mathrm{W}$ - waterlogging stress condition; $\mathrm{W}+\mathrm{SA}-1 \mathrm{mM}$ salicylic acid plus waterlogging stress condition. Data represent means \pm SD of three replicates. For each variable, means with different lowercase letters were significantly different $(P<0.05)$.

Fig. 3. Effects of salicylic acid on $(A)$ net photosynthetic rate $\left(P_{\mathrm{N}}\right) ;(B)$ transpiration rate $(E)$; (C) stomatal conductance $\left(g_{\mathrm{s}}\right)$; and $(D)$ intercellular $\mathrm{CO}_{2}$ concentration $\left(C_{\mathrm{i}}\right)$ in two waxy corn inbred lines under waterlogging conditions. $\mathrm{CK}$ normal watering condition; $\mathrm{CK}+\mathrm{SA}-1 \mathrm{mM}$ salicylic acid plus normal watering condition; W - waterlogging stress condition; $\mathrm{W}+\mathrm{SA}-1 \mathrm{mM}$ salicylic acid plus waterlogging stress condition. Data represent means \pm SD of three replicates. For each variable, means with different lowercase letters were significantly different $(P<0.05)$. 
The changes in $E$ and $g_{\text {s }}$ also exhibited the same trend (Fig. 3B,C).

Chl fluorescence parameters: The fluorescence images showed that the application of SA did not change $F_{v} / F_{m}$, $\Phi_{\mathrm{PSII}}, \mathrm{NPQ}, \mathrm{q}_{\mathrm{P}}$, and Rfd under growth conditions (Fig. 4). Under waterlogging stress conditions, the $F_{\mathrm{v}} / \mathrm{F}_{\mathrm{m}}, \Phi_{\text {PSII }}$, $\mathrm{NPQ}$, and $\mathrm{q}_{\mathrm{P}}$ of SY-MY13 decreased compared with those in $\mathrm{CK}$; Rfd changes were not significant. The $\mathrm{F}_{\mathrm{v}} / \mathrm{F}_{\mathrm{m}}, \mathrm{NPQ}$, and Rfd of SY-XT1 were lower than that in CK; besides, the $\Phi_{\mathrm{PSII}}$ and $\mathrm{q}_{\mathrm{P}}$ were higher than that in $\mathrm{CK}$. The application of SA significantly improved the $\mathrm{F}_{\mathrm{v}} / \mathrm{F}_{\mathrm{m}}, \Phi_{\mathrm{PSII}}, \mathrm{NPQ}, \mathrm{q}_{\mathrm{P}}$, and Rfd of waxy corn seedlings under waterlogging stress, and the increase in $F_{v} / F_{m}$ and Rfd was more pronounced in SY-XT1 than that in SY-MY13.

Stomatal aperture: The stomatal aperture is influenced by multiple mechanisms. The effect of the treatments on the stomatal aperture is shown in Fig. 5. Under non-waterlogging treatments, exogenous SA exerted no effect on the stomata (Fig. 5B,F). However, waterlogging treatment lead to a decrease in stomatal apertures, and the stomatal opening of SY-XT1 significantly decreased compared to that of SY-MY13 seedlings (Fig. 5C,G). Fortunately, the stomatal closure was prevented by treatment with SA, especially in SY-XT1 (Fig. 5H).

Membrane lipid peroxidation and accumulation of ROS: MDA is a direct product of lipid peroxidation. The contents of two major ROS species $\mathrm{O}_{2}{ }^{--}$and $\mathrm{H}_{2} \mathrm{O}_{2}$ were analyzed by histochemical staining and spectrophotometry in the leaves. The MDA content in the leaves slightly decreased by exogenous SA under the normal growth conditions (Fig. 6A,B). The MDA content increased obviously after waterlogging stress, and SY-MY13 and SY-XT1 showed an increase of 43.6 and $136.3 \%$, respectively, suggesting that waterlogging damaged the integrity of the cell membrane system. SY-XT1 more easily accumulated ROS under waterlogging stress compared to SY-MY13. However, exogenous SA markedly decreased the content of MDA under the waterlogging conditions. The contents of $\mathrm{O}_{2}{ }^{-}$and $\mathrm{H}_{2} \mathrm{O}_{2}$ in the two inbred lines slightly decreased by exogenous SA under the normal growth conditions (Fig. $6 C-F$ ). Although $\mathrm{O}_{2}{ }^{--}$and $\mathrm{H}_{2} \mathrm{O}_{2}$ increased significantly in the leaves under the waterlogging stress, exogenous SA application markedly reduced the accumulation of ROS.

Antioxidant enzyme activities: Compared with CK, waterlogging stress altered the activities of antioxidant enzymes and resulted in a significant increase in SOD and PPO. Exogenous SA treatment also regulated the activities of antioxidant enzymes under waterlogging stress. Relative to the control, waterlogging stress significantly increased the SOD and PPO activities of SY-MY13 and SY-XT1 by 97.8 and $64.4 \%$, and 43.2 and $91.9 \%$, respectively. However, waterlogging stress did not affect POD and CAT activities but SA supplementation enhanced the activities of SOD, POD, CAT, and PPO under waterlogging stress (Fig. 7).

\section{Discussion}

Waterlogging stress is one of the most common environ-mental stresses that limit plant productivity. Oxygen limitation causes a drop in root respiration, photosynthesis, and $\mathrm{CO}_{2}$ assimilation in waterlogged soils (Subbaiah and Sachs 2003, Arbona et al. 2008, Gul et al. 2020). Therefore, plants evolved a variety of mechanisms to adapt to waterlogging stress, including morphological and anatomical features, metabolism, and molecular transcriptional regulation (Syed et al. 2015, Lone et al. 2016, Yin et al. 2017, Yin and Komatsu 2017). SA application has been reported to induce tolerance to waterlogging stress (Kumar and Padmanabh 2017, Khalil

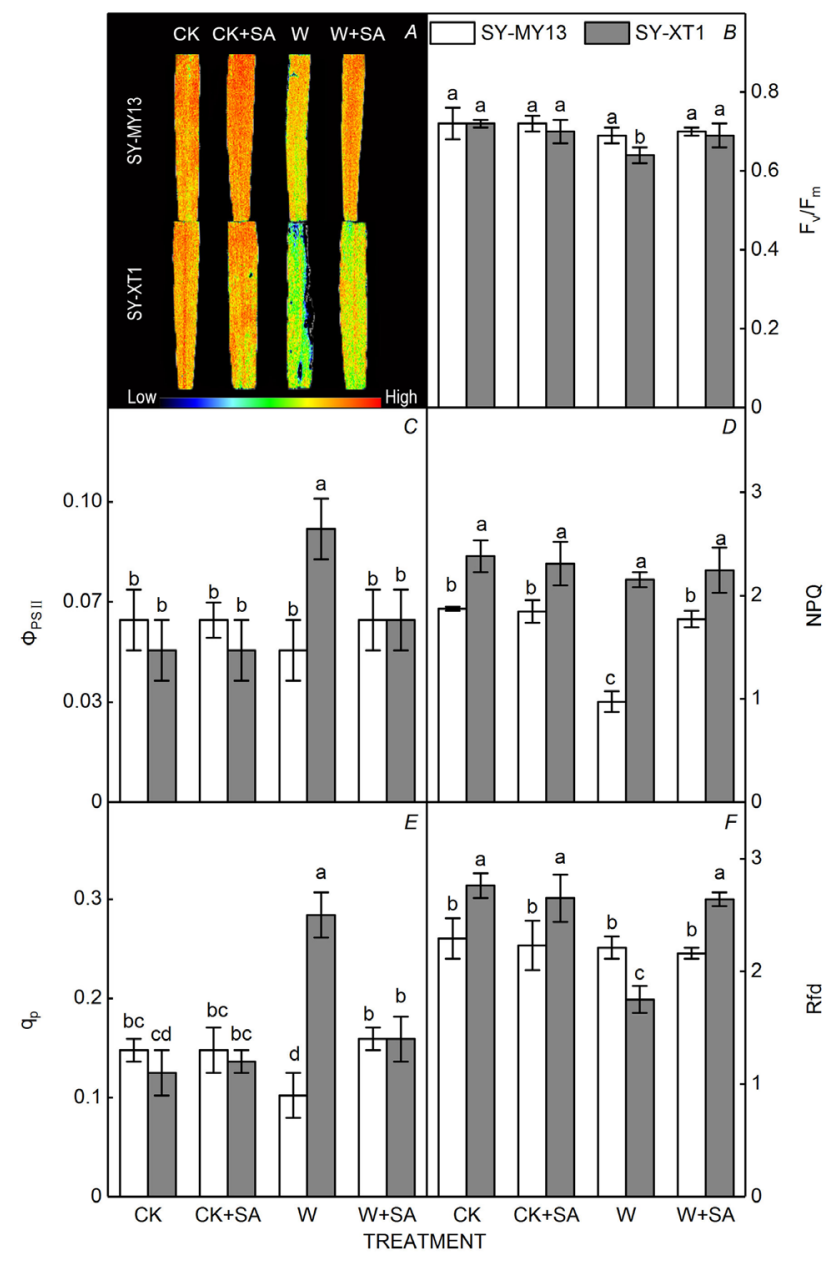

Fig. 4. Effects of salicylic acid on $(A)$ the fluorescence image of maximum quantum yield of PSII $\left(\mathrm{F}_{\mathrm{v}} / \mathrm{F}_{\mathrm{m}}\right) ;(B)$ maximum quantum yield of PSII $\left(\mathrm{F}_{\mathrm{v}} / \mathrm{F}_{\mathrm{m}}\right) ;(C)$ effective quantum yield of PSII $\left(\Phi_{\text {PSII }}\right) ;(D)$ nonphotochemical quenching coefficient $(\mathrm{NPQ}) ;(E)$ photochemical quenching $\left(\mathrm{q}_{\mathrm{P}}\right)$; and $(F)$ steady-state fluorescence decay rate (Rfd) in two waxy corn inbred lines under waterlogging conditions. $\mathrm{CK}$ - normal watering condition; $\mathrm{CK}+\mathrm{SA}-1 \mathrm{mM}$ salicylic acid plus normal watering condition; $\mathrm{W}$ - waterlogging stress condition; $\mathrm{W}+\mathrm{SA}-1 \mathrm{mM}$ salicylic acid plus waterlogging stress condition. Data represent means \pm $\mathrm{SD}$ of three replicates. For each variable, means with different lowercase letters were significantly different $(P<0.05)$. 

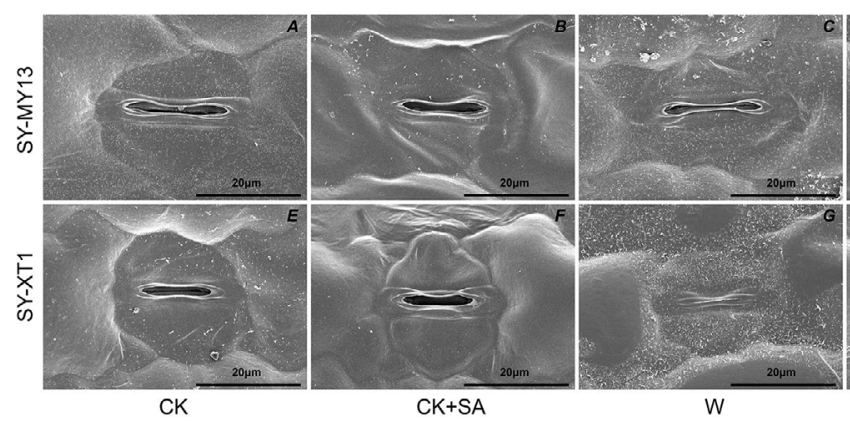

W

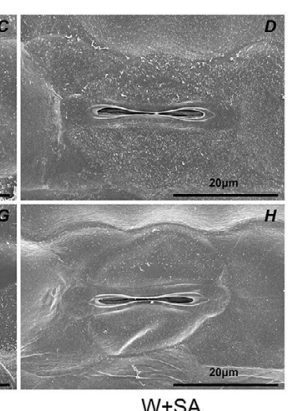

Fig. 5. SEM images of stomata in the leaves of SY-MY13 and SY-XT1. $(A, E)$ Stomata in the leaves of normal watering condition (CK); $(B, F)$ stomata in the leaves of $1 \mathrm{mM}$ salicylic acid plus normal watering condition $(\mathrm{CK}+\mathrm{SA}) ;(C, G)$ stomata in the leaves under waterlogging conditions (W); and $(G, H)$ stomata in the leaves of $1 \mathrm{mM}$ salicylic acid plus waterlogging condition (W $+\mathrm{SA})$. Magnification 2400×, scale bars $20.0 \mu \mathrm{m}$.
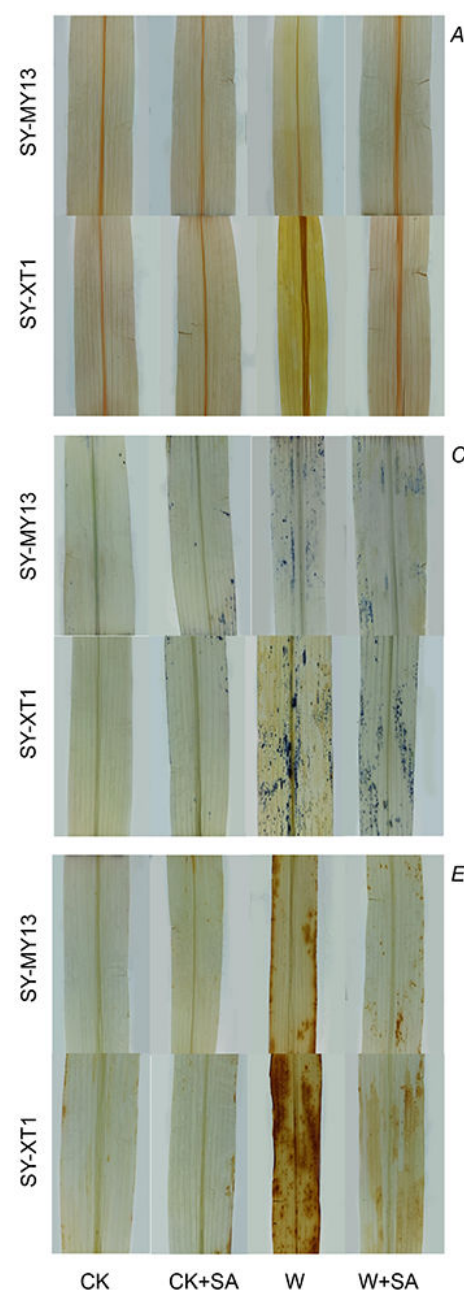

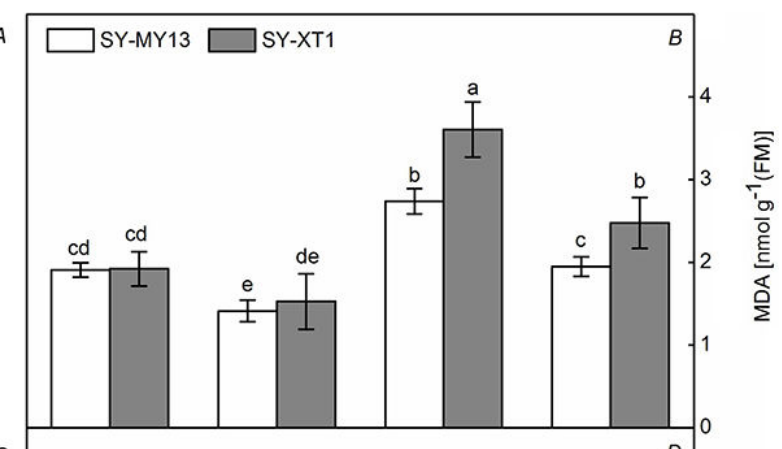

$c$

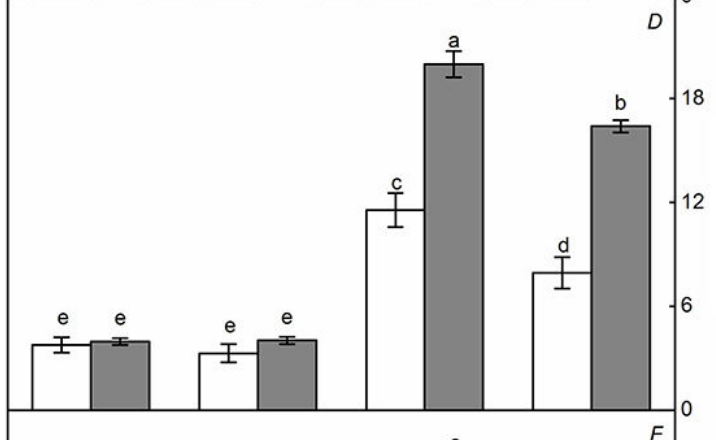

E

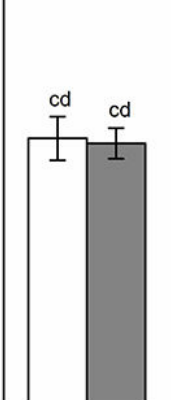

CK

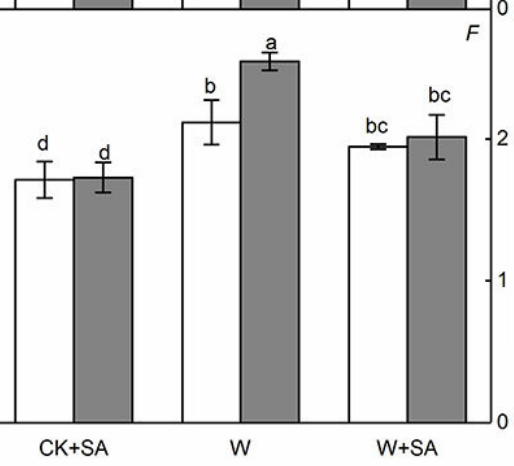

TREATMENT

Fig. 6. Effects of salicylic acid on $(A)$ histochemical staining and $(B)$ the content of MDA; (C) histochemical staining, and $(D)$ the content of $\mathrm{O}_{2}^{--} ;(E)$ histochemical staining, and $(F)$ the content of $\mathrm{H}_{2} \mathrm{O}_{2}$ in two waxy corn inbred lines under waterlogging conditions. CK normal watering condition; $\mathrm{CK}+\mathrm{SA}-1 \mathrm{mM}$ salicylic acid plus normal watering condition; W - waterlogging stress condition; W + SA - $1 \mathrm{mM}$ salicylic acid plus waterlogging stress condition. Data represent means $\pm \mathrm{SD}$ of three replicates. For each variable, means with different lowercase letters were significantly different $(P<0.05)$.

et al. 2018). The present study investigated the protective effects of the application of exogenous SA in waxy corn seedlings exposed to waterlogging stress.

Biomass and photosynthetic capacity are important indicators of plant stress resistance. Chl, as a photosynthetic pigment, is an essential component of the photosynthetic apparatus. Carotenoids are vital in photosynthesis and resistance to adversities. They act as antioxidant single-oxygen scavenger defense system protecting the photosynthetic apparatus from ROS (Yang and Miao 2010, Li et al. 2012); their contents positively correlate with photosynthesis. Waterlogging stress inhibits photosynthesis by accelerating the degradation of pigments and damage the chloroplast structure, accounting for the decrease in growth and biomass ( Xu et al. 2019). In this study, waterlogging stress significantly reduced the biomass of SY-MY13 and SY-XT1; however, large differences existed in FM and DM between SY-MY13 and SY-XT1. SY-MY13 had a higher photosynthetic pigment content compared to SY-XT1 under waterlogging stress. This also explained why the waterlogging-resistant line SY-MY13 could maintain higher biomass under water- 


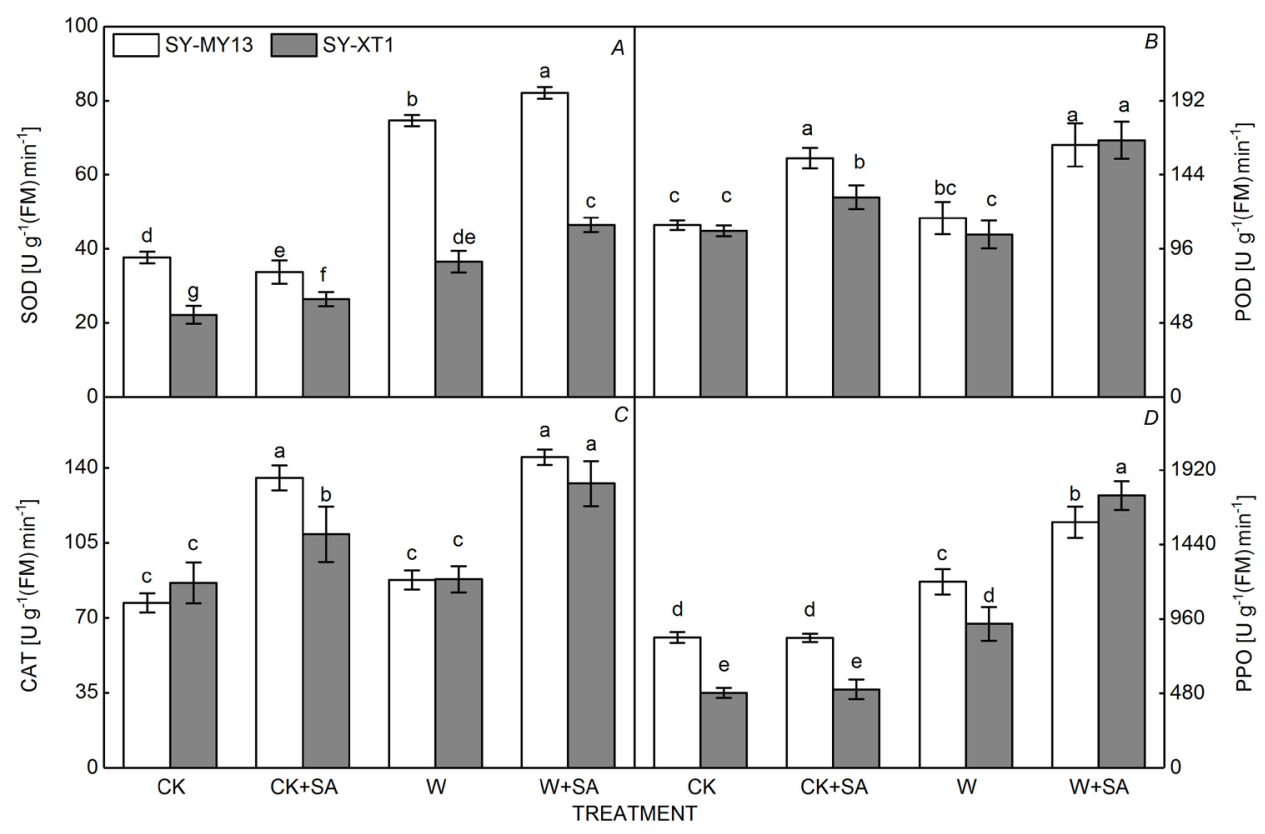

Fig. 7. Effects of salicylic acid on the activity of $(A)$ superoxide dismutase (SOD); $(B)$ peroxidase $(\mathrm{POD}) ;(C)$ catalase $(\mathrm{CAT})$; and $(D)$ polyphenol oxidase (PPO) in two waxy corn inbred lines under waterlogging conditions. $\mathrm{CK}-$ normal watering condition; $\mathrm{CK}+\mathrm{SA}-1 \mathrm{mM}$ salicylic acid plus normal watering condition; W - waterlogging stress condition; $\mathrm{W}+\mathrm{SA}-$ $1 \mathrm{mM}$ salicylic acid plus waterlogging stress condition. Data represent means \pm SD of three replicates. For each variable, means with different lowercase letters were significantly different $(P<0.05)$. logging stress. SA application effectively improves the biosynthesis of photosynthetic pigments. Similarly, in the present study, the contents of Chl after SA treatment significantly increased compared to those after non-SA treatment under waterlogging stress. In this study, treatments with SA resulted in significant and substantial increases in the contents of carotenoids (Fig. 2C). These results might be associated with the capacity of SA to maintain a higher carotenoid content, reduce excessive accumulation of ROS, alleviate oxidative damage of plasmalemma, and maintain internal environment homeostasis, thereby reducing the damage of photosynthetic apparatus and the degradation of Chl. A similar observation was also reported in soybean (Yin and Komatsu 2017).

Photosynthesis is the key process necessary for the growth and development of higher plants; it is also one of the processes most sensitive to waterlogging stress (Sterling et al. 2019, Zhang et al. 2019b). The preliminary experiments in this study revealed that waterlogging stress reduced $P_{\mathrm{N}}, E, g_{\mathrm{s}}$, and $C_{\mathrm{i}}$, and $P_{\mathrm{N}}$ decreased more rapidly in SY-XT1 than that in SY-MY13 (Fig. 3). A similar decline in $P_{\mathrm{N}}, g_{\mathrm{s}}$, and $C_{\mathrm{i}}$ was observed for sorghum by Zhang et al. (2019a). Under waterlogging stress, the $g_{\mathrm{s}}$ of waxy corn leaves significantly declined, causing a decrease in $E$ and $C_{\mathrm{i}}$. The stomatal aperture is influenced by multiple mechanisms, and each stoma is surrounded by a pair of guard cells. Open stomata facilitate $\mathrm{CO}_{2}$ uptake and water loss. Waterlogging stress induces stomatal closure (Ahmed et al. 2002). The results of this study showed a reduction in photosynthetic carbon assimilation because it would then also prevent $\mathrm{CO}_{2}$ from entering the leaves. $\mathrm{CO}_{2}$ is important source for photosynthesis and the decrease of its concentration leads to a decline in $P_{\mathrm{N}}$ in waxy corn leaves. The results of the present study also showed that $E, g_{\mathrm{s}}$, and $C_{\mathrm{i}}$ improved in waxy corn leaves under exogenous SA treatment with waterlogging stress compared to waterlogging stress alone, similarly as $P_{\mathrm{N}}$. These results suggested that the exogenous SA treatment might have regulated the open status of stomata under waterlogging stress.

Chl fluorescence measurements could provide information on the status of the photosynthetic apparatus in response to various environmental factors, allowing early detection of various environmental stresses, even before the appearance of visible symptoms (Lang et al. 1996, Lichtenthaler et al. 2005). However, few studies reported on the combination of $\mathrm{Chl}$ fluorescence and multicolor fluorescence imaging techniques as a means to study the phenotyping of waxy corn response to waterlogging stress. Several studies demonstrated that severe or prolonged waterlogging led to photoinhibition in the PSII reaction center (Zheng et al. 2009, Gao et al. 2017, Yan et al. 2018). The decrease in $F_{v} / F_{m}$ reflected the damage of photochemical reactions, accompanied by the interdict of electron transport (inhibition of electron transfer). In the present study, $F_{\mathrm{v}} / \mathrm{F}_{\mathrm{m}}, \Phi_{\mathrm{PSII}}$, and $\mathrm{q}_{\mathrm{P}}$ of SY-MY13 and SY-XT1 significantly decreased under the waterlogging stress compared with CK. However, the decrease in the $\mathrm{F}_{\mathrm{v}} / \mathrm{F}_{\mathrm{m}}$ after the exogenous SA treatment was lesser than that after the non-SA-treatment, suggesting that SA application significantly improved the photosynthetic capacity of PSII under the waterlogging stress. Rfd reflected leaf activity. Our results showed that the Rfd of leaves after SA treatment increased under waterlogging stress compared to non-SA-treatment, indicating that SA helped improve the leaf activity.

When plants were exposed to waterlogging stress, ROS was overproduced and accumulated, further leading to the generation of oxidative stress (Sairam et al. 2011, Patel et al. 2019). Plants minimize oxidative stress by activating an enzymatic antioxidant defense system, such as SOD, CAT, and POD, to scavenge ROS. In this study, waterlogging stress altered the activities of antioxidant enzymes and resulted in significantly higher SOD and PPO in 
SY-MY13 and SY-XT1. The research suggested that supplementation with SA decreased ROS biosynthesis, and environmental factors induced oxidative stress. Nie et al. (2018) concluded that exogenous SA enhanced the ROS-scavenging system, reduced oxidative damage, and alleviated lipid peroxidation, thereby improving the alkaline tolerance of cucumber plants. Similar changes were also observed in the antioxidant system under drought stress in safflower (Chavoushi et al. 2020), nickel stress in mustard (Zaid et al. 2019), and glyphosate-induced oxidative stress in Hordeum vulgare L. (Spormann et al. 2019). Therefore, supplementation with SA enhanced the activities of SOD, POD, and CAT under environmental stress, which helped reduce the ROS content and further provided a reducing environment for efficient metabolic activities. This study showed that waterlogging stress increased SOD, CAT, POD, and PPO activities, and supplementation of waterlogging-stressed waxy corn with SA increased antioxidant defense system activities, which reduced the ROS content of SY-MY13 and SY-XT1. These results indicated that the exogenous SA pretreatment improved waxy corn waterlogging tolerance by regulating antioxidant enzymes.

Conclusions: Waterlogging stress negatively influenced the morphology, plant height, biomass, and photosynthetic characteristics of waxy corn, obstructing growth and development. SY-MY13 exhibited better growth and photosynthesis than that of SY-XT1 under waterlogging; this was due to SY-MY13 possessed excellent ROSscavenging ability. The application of exogenous SA could not only reduce the accumulation of ROS and affect antioxidative enzymes but also improved photosynthesis in leaves and promoted the growth of seedlings. Therefore, the application of exogenous SA could alleviate the waterlogging-induced damages, improve waterlogging tolerance in waxy corn through the activation of antioxidative defense systems, eliminate ROS, and improve photosynthesis efficiency in leaves. In conclusion, this study provided a comprehensive understanding of SA-mediated waterlogging stress resistance in waxy corn seedlings.

\section{References}

Abedi T., Pakniyat H.: Antioxidant enzyme changes in response to drought stress in ten cultivars of oilseed rape (Brassica napus L.). - Czech J. Genet. Plant Breed. 46: 27-34, 2010.

Ahmed S., Nawata E., Hosokawa M. et al:: Alterations in photosynthesis and some antioxidant enzymatic activities of mungbean subjected to waterlogging. - Plant Sci. 163: $117-123,2002$

Anee T.I., Nahar K., Rahman A. et al.: Oxidative damage and antioxidant defense in Sesamum indicum after different waterlogging durations. - Plants-Basel 8: 196, 2019.

Arbona V., Hossain Z., López-Climent M.F. et al.: Antioxidant enzymatic activity is linked to waterlogging stress tolerance in citrus. - Physiol. Plantarum 132: 452-466, 2008.

Bai T., Li C., Ma F. et al.: Exogenous salicylic acid alleviates growth inhibition and oxidative stress induced by hypoxia stress in Malus robusta Rehd. - J. Plant. Growth Regul. 28: 358-366, 2009
Bansal R., Srivastava J.P.: Antioxidative defense system in pigeonpea roots under waterlogging stress. - Acta Physiol. Plant. 34: 515-522, 2012.

Cai M.L., Zhang Q.L., Zheng X.T. et al.: Comparison of leaves and stems of Peaderia scandens (Lour.) Merr. in tolerance to low temperature. - Photosynthetica 58: 846-852, 2020.

Chávez-Arias C.C., Gómez-Caro S., Restrepo-Díaz H.: Mitigation of the impact of vascular wilt and soil hypoxia on cape gooseberry plants by foliar application of synthetic elicitors. - HortScience 55: 121-132, 2019.

Chavoushi M., Najafi F., Salimi A., Angaji S.A.: Effect of salicylic acid and sodium nitroprusside on growth parameters, photosynthetic pigments and secondary metabolites of safflower under drought stress. - Sci. Hortic.-Amsterdam 259: 108823, 2020

Dar M.H., Zaidi N.W., Waza S.A. et al.: No yield penalty under favorable conditions paving the way for successful adoption of flood tolerant rice. - Sci. Rep.-UK 8: 9245, 2018.

Fariduddin Q., Khan T.A., Yusuf M. et al.: Ameliorative role of salicylic acid and spermidine in the presence of excess salt in Lycopersicon esculentum. - Photosynthetica 56: 750-762, 2017.

Fukao T., Barrera-Figueroa B.E., Juntawong P., Peña-Castro J.M.: Submergence and waterlogging stress in plants: A review highlighting research opportunities and understudied aspects. - Front. Plant Sci. 10: 340, 2019.

Gao Y., Xia J., Chen Y. et al:: Effects of extreme soil water stress on photosynthetic efficiency and water consumption characteristics of Tamarix chinensis in China's Yellow River Delta. - J. Forestry. Res. 28: 491-501, 2017.

Gill M.B., Zeng F., Shabala L. et al:: Identification of QTL related to ROS formation under hypoxia and their association with waterlogging and salt tolerance in barley. - Int. J. Mol. Sci. 20: 699, 2019.

Gul F., Arfan M., Shahbaz M., Basra S.M.A.: Salicylic acid seed priming modulates morphology, nutrient relations and photosynthetic attributes of wheat grown under cadmium stress. - Int. J. Agric. Biol. 23: 197-204, 2020.

Jaiswal A., Srivastava J.P.: Nitric oxide mitigates waterlogging stress by regulating antioxidative defense mechanism in maize (Zea mays L.) root. - Bangl. J. Bot. 45: 517-524, 2016.

Jia L., Qin X., Lyu D. et al.: ROS production and scavenging in three cherry rootstocks under short-term waterlogging conditions. - Sci. Hortic.-Amsterdam 257: 108647, 2019.

Kamal A.H.M., Komatsu S.: Jasmonic acid induced protein response to biophoton emissions and flooding stress in soybean. - J. Proteomics 133: 33-47, 2016.

Ketthaisong D., Suriharn B., Tangwongchai R., Lertrat K.: Combining ability analysis in complete diallel cross of waxy corn (Zea mays var. ceratina) for starch pasting viscosity characteristics. - Sci. Hortic.-Amsterdam 175: 229-235, 2014.

Khalil N., Fekry M., Bishr M. et al.: Foliar spraying of salicylic acid induced accumulation of phenolics, increased radical scavenging activity and modified the composition of the essential oil of water stressed Thymus vulgaris L. - Plant. Physiol. Bioch. 123: 65-74, 2018.

Kumar S.S., Kumar S.A., Padmanabh D.: Modulating effect of salicylic acid in tomato plants in response to waterlogging stress. - Int. J. Agric. Environ. Biotech. 10: 31-37, 2017.

Lang M., Lichtenthaler H.K., Sowinska M. et al.: Fluorescence imaging of water and temperature stress in plant leaves. J. Plant Physiol. 148: 613-621, 1996.

Li J., Pang Z., Trivedi P. et al.: 'Candidatus Liberibacter asiaticus' encodes a functional salicylic acid (sa) hydroxylase that degrades sa to suppress plant defenses. - Mol. Plant Microbe In. 30: 620-630, 2017. 
Li R., Shang H., Wu H. et al.: Thermal inactivation kinetics and effects of drying methods on the phenolic profile and antioxidant activities of chicory (Cichorium intybus L.) leaves. - Sci. Rep.-UK 8: 9529, 2018.

Li X.M., Zhang L.H., Li Y.Y. et al.: Changes in photosynthesis, antioxidant enzymes and lipid peroxidation in soybean seedlings exposed to UV-B radiation and/or Cd. - Plant Soil 352: 377-387, 2012.

Lichtenthaler H.K., Langsdorf G., Lenk S., Buschmann C.: Chlorophyll fluorescence imaging of photosynthetic activity with the flash-lamp fluorescence imaging system. Photosynthetica 43: 355-369, 2005.

Lone A.A., Khan M.H., Dar Z.A. et al.: Breeding strategies for improving growth and yield under waterlogging conditions in maize: A review. - Maydica 61: M2, 2016.

Moravcová S., Tůma J., Kovalíková Dučaiová Z. et al.: Influence of salicylic acid pretreatment on seeds germination and some defence mechanisms of Zea mays plants under copper stress. - Plant. Physiol. Bioch. 122: 19-30, 2018.

Nie W., Gong B., Chen Y. et al.: Photosynthetic capacity, ion homeostasis and reactive oxygen metabolism were involved in exogenous salicylic acid increasing cucumber seedlings tolerance to alkaline stress. - Sci. Hortic.-Amsterdam 235: 413-423, 2018.

Ohkawa H., Ohishi N., Yagi K.: Assay for lipid peroxides in animal tissues by thiobarbituric acid reaction. - Anal. Biochem. 95: 351-358, 1979.

Otie V., Ping A., Udo I., Eneji E.: Brassinolide effects on maize (Zea mays L.) growth and yield under waterlogged conditions. - J. Plant Nutr. 42: 954-969, 2019.

Panozzo A., Dal Cortivo C., Ferrari M. et al:: Morphological changes and expressions of $A O X 1 A, C Y P 81 D 8$, and putative $P F P$ genes in a large set of commercial maize hybrids under extreme waterlogging. - Front. Plant Sci. 10: 62, 2019.

Park J.S., Lee E.J.: Waterlogging induced oxidative stress and the mortality of the Antarctic plant, Deschampsia antarctica. J. Ecol. Environ. 43: 29, 2019.

Patel M.K., Pandey S., Burritt D.J., Tran L.-S.P.: Plant responses to low-oxygen stress: Interplay between ROS and NO signaling pathways. - Environ. Exp. Bot. 161: 134-142, 2019.

Perera-Castro A.V., Brito P., González-Rodríguez A.M.: Change in thermic limits and acclimation assessment for an alpine plant by chlorophyll fluorescence analysis: $\mathrm{F}_{\mathrm{v}} / \mathrm{F}_{\mathrm{m}} v s . \mathrm{R}_{\mathrm{fd} .}$ Photosynthetica 56: 527-536, 2018.

Pirovani C.P., Carvalho H.A.S., Machado R.C.R. et al.: Protein extraction for proteome analysis from cacao leaves and meristems, organs infected by Moniliophthora perniciosa, the causal agent of the witches' broom disease. - Electrophoresis 29: 2391-2401, 2008.

Posso D.A., Borella J., Reissig G.N., Bacarin M.A.: Root flooding-induced changes in the dynamic dissipation of the photosynthetic energy of common bean plants. - Acta Physiol. Plant. 40: 212, 2018.

Ren B., Hu J., Zhang J. et al.: Spraying exogenous synthetic cytokinin 6-benzyladenine following the waterlogging improves grain growth of waterlogged maize in the field. J. Agron. Crop Sci. 205: 616-624, 2019.

Ren B., Zhang J., Dong S. et al.: Responses of carbon metabolism and antioxidant system of summer maize to waterlogging at different stages. - J. Agron. Crop Sci. 204: 505-514, $2018 \mathrm{a}$.

Ren B., Zhang J., Dong S. et al.: Exogenous 6-benzyladenine improves antioxidative system and carbon metabolism of summer maize waterlogged in the field. - J. Agron. Crop Sci. 204: 175-184, 2018b.

Ren C.G., Kong C.C., Yan K. et al.: Elucidation of the molecular responses to waterlogging in Sesbania cannabina roots by transcriptome profiling. - Sci. Rep.-UK 7: 9256, 2017.

Sairam R.K., Dharmar K., Chinnusamy V. et al.: NADPH oxidase as the source of ROS produced under waterlogging in roots of mung bean. - Biol. Plantarum 55: 741-746, 2011.

Sayed S.A.E.: Ameliorative effects of salicylic acid on saltstressed Lupinus albus plants growing under oxygen deficiency. - Phyton 54: 101-122, 2014.

Spormann S., Soares C., Fidalgo F.: Salicylic acid alleviates glyphosate-induced oxidative stress in Hordeum vulgare L. J. Environ. Manage. 241: 226-234, 2019.

Sterling A., Rodríguez N., Quiceno E. et al.: Dynamics of photosynthetic responses in 10 rubber tree (Hevea brasiliensis) clones in Colombian Amazon: Implications for breeding strategies. - PLoS ONE 14: e0226254, 2019.

Subbaiah C.C., Sachs M.M.: Clacium-mediated responses of maize to oxygen deprivation. - Russ. J. Plant Physl+ 50: 752 761, 2003

Syed N.H., Prince S.J., Mutava R.N. et al.: Core clock, SUB1, and ABAR genes mediate flooding and drought responses via alternative splicing in soybean. - J. Exp. Bot. 66: 7129-7149, 2015.

Tian L.X., Li J., Bi W.S. et al.: Effects of waterlogging stress at different growth stages on the photosynthetic characteristics and grain yield of spring maize (Zea mays L.) under field conditions. - Agr. Water Manage. 218: 250-258, 2019.

Wang C.Y.: Effect of temperature preconditioning on catalase, peroxidase, and superoxide dismutase in chilled zucchini squash. - Postharvest Biol. Tec. 5: 67-76, 1995.

Wang H., Chen Y., Hu W. et al.: Short-term soil-waterlogging contributes to cotton cross tolerance to chronic elevated temperature by regulating ROS metabolism in the subtending leaf. - Plant Physiol. Bioch. 139: 333-341, 2019b.

Wang J., Lv X., Wang H. et al:: Morpho-anatomical and physiological characteristics responses of a paired nearisogenic lines of waxy corn to waterlogging. - Emir. J. Food Agr. 31: 951-957, 2019a.

Wassie M., Zhang W., Zhang Q. et al.: Exogenous salicylic acid ameliorates heat stress-induced damages and improves growth and photosynthetic efficiency in alfalfa (Medicago sativa L.). - Ecotox. Environ. Safe. 191: 110206, 2020.

Wellburn A.R.: The spectral determination of chlorophylls $a$ and $b$, as well as total carotenoids, using various solvents with spectrophotometers of different resolution. - J. Plant. Physiol. 144: 307-313, 1994.

Wollmer A.-C., Pitann B., Mühling K.H.: Waterlogging events during stem elongation or flowering affect yield of oilseed rape (Brassica napus L.) but not seed quality. - J. Agron. Crop Sci. 204: 165-174, 2018.

Xia X.J., Wang Y.J., Zhou Y.H. et al.: Reactive oxygen species are involved in brassinosteroid-induced stress tolerance in cucumber. - Plant Physiol. 150: 801-814, 2009.

Xu J., Zhu Y., Ge Q. et al.: Comparative physiological responses of Solanum nigrum and Solanum torvum to cadmium stress. New Phytol. 196: 125-138, 2012.

Xu L., Pan R., Shabala L. et al.: Temperature influences waterlogging stress-induced damage in Arabidopsis through the regulation of photosynthesis and hypoxia-related genes. Plant Growth Regul. 89: 143-152, 2019.

Xu X., Ji J., Ma X. et al.: Comparative proteomic analysis provides insight into the key proteins involved in cucumber (Cucumis sativus L.) adventitious root emergence under waterlogging stress. - Front. Plant Sci. 7: 1515, 2016.

Yan K., Zhao S., Cui M. et al.: Vulnerability of photosynthesis and photosystem I in Jerusalem artichoke (Helianthus tuberosus L.) exposed to waterlogging. - Plant. Physiol. Bioch. 125: 239-246, 2018. 
Yang F., Miao L.F.: Adaptive responses to progressive drought stress in two poplar species originating from different altitudes. - Silva Fenn. 44: 23-37, 2010.

Yin X., Hiraga S., Hajika M. et al.: Transcriptomic analysis reveals the flooding tolerant mechanism in flooding tolerant line and abscisic acid treated soybean. - Plant Mol. Biol. 93: 479-496, 2017

Yin X., Komatsu S.: Comprehensive analysis of response and tolerant mechanisms in early-stage soybean at initial-flooding stress. - J. Proteomics 169: 225-232, 2017.

Yousefzadeh Najafabadi M., Ehsanzadeh P.: Photosynthetic and antioxidative upregulation in drought-stressed sesame (Sesamum indicum L.) subjected to foliar-applied salicylic acid. - Photosynthetica 55: 611-622, 2017.

Zaid A., Mohammad F., Wani S.H., Siddique K.M.H.: Salicylic acid enhances nickel stress tolerance by up-regulating antioxidant defense and glyoxalase systems in mustard plants. - Ecotox. Environ. Safe. 180: 575-587, 2019.
Zhang M., He S., Zhan Y. et al.: Exogenous melatonin reduces the inhibitory effect of osmotic stress on photosynthesis in soybean. - PLoS ONE 14: e0226542, 2019b.

Zhang R.D., Zhou Y.F., Yue Z.X. et al.: Changes in photosynthesis, chloroplast ultrastructure, and antioxidant metabolism in leaves of sorghum under waterlogging stress. Photosynthetica 57: 1076-1083, 2019a.

Zheng C., Jiang D., Liu F. et al.: Effects of salt and waterlogging stresses and their combination on leaf photosynthesis, chloroplast ATP synthesis, and antioxidant capacity in wheat. - Plant Sci. 176: 575-582, 2009.

Zhu M., Wang J., Li F., Shi Z.: Physiological and photosynthesis response of popcorn inbred seedings to waterlogging stress. Pak. J. Bot. 47: 2069-2075, 2015.

Zhu X., Shi H., Li X., Jin S.: Salicylic acid induces physiological and biochemical changes in peony under waterlogging stress. - Acta Sci. Pol.-Hortoru. 19: 41-52, 2020.

(C) The authors. This is an open access article distributed under the terms of the Creative Commons BY-NC-ND Licence. 